\title{
UMA PROPOSTA DE SEQUÊNCIA DIDÁTICA PARA ENSINO DE GRÁFICOS ESTATÍSTICOS A PARTIR DA INTERSECCIONALIDADE ENTRE SEXO E RAÇA COM TEMÁTICAS DE UMA ANÁLISE SOCIOECONÔMICA
}

UNA PROPUESTA SECUENCIAL DIDÁCTICA PARA ENSENANZA DE GRÁFICOS ESTADÍSTICOS SOBRE LA INTERSECCIONALIDAD ENTRE SEXO Y RAZA CON TEMATICA DE ANÁLISIS SOCIOECONÓMICO

\section{A PROPOSAL OF TEACHING SEQUENCE FOR TEACHING STATISTICAL GRAPHICS FROM THE INTERSECTIONALITY BETWEEN GENDER AND RACE WITH THEMES FROM A SOCIOECONOMIC ANALYSIS}

Ivanise Gomes Arcanjo Diniz

Secretaria de Educação do Estado da Bahia

Leandro do Nascimento Diniz Universidade Federal do Recôncavo da Bahia - UFRB

Luís Rodrigo Ferreira Santos Universidade Federal do Recôncavo da Bahia - UFRB

\section{RESUMO}

Este artigo tem por objetivo analisar uma atividade construída com foco na interpretação de gráficos estatísticos a partir de temáticas que versem sobre a interseccionalidade de sexo e raça, considerando aspectos econômicos e sociais das cidades de Salvador-BA e São Paulo-SP, entre 2011 e 2017. A importância deste tema consiste em apresentar discussões referentes à desigualdade racial, sobretudo das mulheres negras, no mercado de trabalho e sua visibilidade é relevante considerando a persistência do racismo estrutural em diferentes setores econômicos, bem como na ausência de equidade social para a população negra. Apresenta-se um Caso de Ensino com uma abordagem qualitativa, para analisar de forma crítica e reflexiva os dados estatísticos apresentados através de órgãos e instituições de pesquisa nacional. Os dados serviram para a construção de atividades destinadas aos (às) alunos (as) de Ensino Médio da 


\title{
UMA PROPOSTA DE SEQUÊNCIA DIDÁTICA PARA ENSINO DE GRÁFICOS ESTATÍSTICOS A PARTIR DA INTERSECCIONALIDADE ENTRE SEXO E RAÇA COM TEMÁTICAS DE UMA ANÁLISE SOCIOECONÔMICA
}

Educação Básica para discutir, a partir de análises de gráficos, o lócus ocupado pela mulher negra na sociedade brasileira, tomando como amostra as cidades já citadas, além das regiões do país em que se situam. Portanto, trazê-las para esta discussão torna-se relevante, já que o problema do racismo estrutural ainda é visível na sociedade, particularmente no mercado de trabalho, foco deste estudo. Assim, discutir essa temática é necessário para que estudantes possam analisar e compreender, a partir de um olhar crítico e reflexivo e por meio da interpretação de gráficos estatísticos de dados sobre educação e renda, o lugar da mulher negra na sociedade.

Palavras-chave: Interseccionalidade entre Sexo e Raça. Aspectos Econômicos. Desigualdade racial. Gráficos Estatísticos.

\section{RESUMEN}

Este artículo tiene por objetivo analizar una actividad construida con el foco en la interpretación de los gráficos estadísticos a partir de la temática acerca de la interseccionalidad de sexo y raza, según los aspectos económicos y sociales de las ciudades de Salvador-BA y Sao Paulo-SP entre 2011 y 2017. La importancia de este tema consiste en presentar discusiones con referencia a la desigualdad racial, sobre todo de las mujeres negras en el mercado de trabajo. Su visibilidad es relevante considerándose la persistencia del racismo estructural en diferentes sectores económicos, así como la ausencia de equidad social para la población negra. Aquí se presenta un Caso de Enseñanza con un abordaje cualitativo, para análisis de forma crítica y reflexiva de datos estadísticos a través de órganos y instituciones de pesquisa nacional. Los datos fueron utilizados para la construcción de actividades y discusiones asignadas a alumnos de la preparatoria y la secundaria, a partir de los análisis de los gráficos, y el lugar ocupado por la mujer negra en la sociedad brasileña, tomando como muestras de las ciudades aquí mencionadas, además de las regiones del país en que estas se sitúan. Por lo tanto, traer ese tema para discusión es de suma importancia, visto que el problema del racismo estructural es visible en la sociedad, especialmente en el mercado de trabajo, que es el foco de ese estudio. Así que discutir ese tema es necesario para que los estudiantes puedan analizar y comprender, desde un punto de vista crítico y reflexivo, y a través de la interpretación de gráficos estadísticos y de datos acerca de la educación y los ingresos, el lugar ocupado por la mujer negra en la sociedad.

Palabras clave: Interseccionalidad entre Sexo y Raza. Aspectos Económicos. Desigualdad racial. Gráficos estadísticos.

\begin{abstract}
This article aims to analyze an activity built with a focus on the interpretation of statistical graphs based on themes that deal with the intersectionality of sex and race, considering economic and social aspects of the cities of Salvador-BA and São Paulo-SP, between 2011 and 2017. The importance of this theme is to present discussions regarding racial inequality, especially of black women, in the labor market and its visibility is relevant considering the persistence of structural racism in different economic sectors, as well as in the absence of social equity for the black population. A Teaching Case with a qualitative approach is presented, in
\end{abstract}

Revista RBBA $\mid$ Revista Binacional Brasil Argentina 


\section{UMA PROPOSTA DE SEQUÊNCIA DIDÁTICA PARA ENSINO DE GRÁFICOS ESTATÍSTICOS A PARTIR DA INTERSECCIONALIDADE ENTRE SEXO E RAÇA COM TEMÁTICAS DE UMA ANÁLISE SOCIOECONÔMICA}

order to critically and reflexively analyze the statistical data presented through national research bodies and institutions. The data were used to build activities for high school students in basic education to discuss, based on graphic analysis, the locus occupied by black women in Brazilian society, taking as a sample the cities already mentioned, in addition to the regions of the country in which they are located. Therefore, bringing them into this discussion becomes relevant, since the problem of structural racism is still visible in society, particularly in the labor market, the focus of this study. Thus, discussing this theme is necessary so that students can analyze and understand, from a critical and reflective look and through the interpretation of statistical graphs of data on education and income, the place of black women in society.

Keywords: Intersectionality between. Sex and Race. Economic Aspects. Racial inequality. Statistical Graphs.

\section{INTRODUÇÃO}

O objetivo deste artigo é analisar uma atividade construída com foco na interpretação de gráficos estatísticos a partir de temáticas que versem sobre a interseccionalidade de gênero e raça sobre aspectos econômicos e sociais das cidades de Salvador-BA e São Paulo-SP, no período de 2011 a 2017, por meio de um Caso de Ensino. A imersão de um dos autores deste artigo no contexto das escolas públicas de ensino médio, como docente, contribuiu para criar condições para reflexões sobre significados, crenças, valores e atitudes, fenômenos e processos vivenciados por alunos (MINAYO, 2004). Trata-se de um trabalho teórico, que proporá discussões sobre o processo de ensino e aprendizagem da Estatística em um contexto sobre renda e educação, com foco na mulher negra.

A escolha pelas cidades mencionadas se deve ao fato de estas serem reconhecidamente de maior população negrai, no caso de Salvador, e parda, em São Paulo. Além disso, Salvador é considerada um centro da cultura afro-brasileira e com maior influência africana na gastronomia, religião, cultura e arte. São Paulo também foi escolhida pelo fato de ser a cidade mais populosa do Brasil, de maior diversidade cultural, com influência de diferentes povos e maior contingente nordestino entre as capitais brasileiras (AGÊNCIA DO BRASIL, 2018). Também, é considerada uma cidade que, desde a década de 1930, destacava-se pela sua média anual de produção industrial e tecnológica (CANO, 2007).

Assim sendo, isto motivou os autores a realizarem esta pesquisa, tendo em vista os desequilíbrios regionais nos diferentes aspectos sociais, econômicos e de setores de produção entre estas cidades. Esse desequilíbrio reflete na oportunidade de trabalho e isto justifica o

Revista RBBA Revista Binacional Brasil Argentina 


\section{UMA PROPOSTA DE SEQUÊNCIA DIDÁTICA PARA ENSINO DE GRÁFICOS ESTATÍSTICOS A PARTIR DA INTERSECCIONALIDADE ENTRE SEXO E RAÇA COM TEMÁTICAS DE UMA ANÁLISE SOCIOECONÔMICA}

grande contingente de nordestinos em São Paulo-SP. A dificuldade de empregabilidade no Nordeste começa no êxodo rural, em meados do século XX, migrando para as cidades de grandes centros industriais do país, a exemplo de São Paulo-SP. Em 2017, a taxa de desemprego de Salvador-BA foi de 22,9\%, considerando que o nordeste possuía 44,8\% da população em situação de pobreza. Em São Paulo-SP, a taxa de desemprego era de 17,3\%, considerando o Sudeste com 17,4\% na situação de pobreza, conforme o Instituto Brasileiro de Geografia e Estatística - IBGE ${ }^{\mathrm{ii}}$ (AGÊNCIA DO BRASIL, 2018) e o Departamento Intersindical de Estatística e Estudos Socioeconômicos - DIEESE (DIEESE, 2018). Tendo em vista estes elementos, questiona-se: como estes dados são apresentados e discutidos ao serem comparados à situação da população negra, em particular da mulher negra?

Este questionamento foi fomentado a partir das discussões ocorridas em duas disciplinas cursadas no doutorado pela segunda autora deste artigo. Na disciplina "economia brasileira", discutiu-se o percurso sobre o desenvolvimento econômico no Brasil e suas relações com outros países, da década de 1930 até os dias atuais. Entre os temas abordados em aula, considera-se importante o resgate histórico da origem do crescimento da era industrial no Brasil e sua necessidade de formação de mão de obra qualificada, respeitando a prerrogativa do êxodo rural e da compreensão da história do lugar dessa mulher negra no mercado de trabalho entre os anos de 1940 e 1970. Entre os economistas referenciados, destaca-se SERRA, José; TAVARES, Maria da Conceição; LESSA, Carlos e LANGONI, Carlos Geraldo.

A outra disciplina, que também contribuiu para a inquietação do questionamento, chama-se "Descolonização de saberes: contribuições da ciência africana e afrodiaspórica". Neste componente curricular, discutiu-se, dentre as temáticas, as ações afirmativas, os aspectos históricos sobre o mito da democracia racial e a mestiçagem no Brasil (1889-1930) e o genocídio do negro brasileiro: processo de um racismo mascarado.

Neste artigo, tem-se o foco nas discussões pautadas em "Mulheres, Classe e Raça", da autora Ângela Davis (2016), em que é abordada a interseccionalidade de gênero, raça e classe, ressaltando o protagonismo e ativismo acerca da equidade de direitos (vida, representatividade, trabalho, educação, família etc.), ainda muito sucumbidos, da mulher negra na sociedade. Além de Ângela Davis, outras autoras, como Djamila Ribeiro, também serão referenciadas. 


\section{UMA PROPOSTA DE SEQUÊNCIA DIDÁTICA PARA ENSINO DE GRÁFICOS ESTATÍSTICOS A PARTIR DA INTERSECCIONALIDADE ENTRE SEXO E RAÇA COM TEMÁTICAS DE UMA ANÁLISE SOCIOECONÔMICA}

Assim, para contemplar essas temáticas, será desenvolvida uma breve abordagem histórica, política e econômica do Brasil, considerando-se a ascensão do desenvolvimento da economia brasileira e discutindo-se como isso impactou a formação profissional da população negra. Em seguida, serão apresentadas as literaturas que apontam as desigualdades de gênero e raça, problematizando a invisibilidade da população negra no âmbito da produtividade de trabalho e formação profissional no país. Aborda-se, neste sentido, a Educação Estatística, com foco na interpretação de gráficos estatísticos e no letramento estatístico. Por fim, será apresentado e analisado um conjunto de atividades, a partir da análise de gráficos estatísticos da realidade da população negra no mercado de trabalho e no âmbito educacional, entre os anos de 2011 e 2017, com o intuito de contribuir com alternativas de atividades que possam inserir a educação estatística no ensino a partir de estudos, interpretações e discussões que despertem um novo olhar sobre o ensino de matemática para as desigualdades raciais.

Um dos motivos para a escolha deste nível de ensino é o fato de pesquisadores, como Sá, Silva e Samá (2015), destacarem os baixos níveis de compreensão e interpretação dos dados estatísticos de alunos do $3^{\circ}$ ano do ensino médio, no contexto que investigaram, a partir das competências e habilidades requeridas na prova do Exame Nacional do Ensino Médio (ENEM). Aponta-se, desta forma, a necessidade de novos estudos sobre a temática. Além disso, autores como Carvalho, Monteiro e Campos (2010) pontuam a necessidade dos gráficos estatísticos, presentes nas questões para os alunos interpretarem, não focarem apenas na aprendizagem de conteúdos estatísticos e matemáticos, mas alavancarem temas do seu contexto social, pois, assim, criam-se condições favoráveis para que questionem os dados apresentados.

A intenção dessa proposta didática consiste no uso de dados estatísticos, para além do texto antropológico, a fim de proporcionar nas instituições escolares, sobretudo nas escolas públicas de Ensino Médio, de público majoritariamente negro, debate e análise de uma realidade social, econômica e política. Vale ressaltar que a importância dessa temática se justifica, também, por ser uma discussão ainda pouco identificada na literatura.

Pretende-se, ainda, apresentar reflexões que versem sobre essas questões: Quais são os papéis dos gráficos? Quais fontes foram utilizadas para a construção dos gráficos? Quais interpretações podem ser extraídas desses gráficos? Para além dos números e dos cálculos, buscou-se proporcionar, através da simbologia das informações apresentadas, o entendimento 


\section{UMA PROPOSTA DE SEQUÊNCIA DIDÁTICA PARA ENSINO DE GRÁFICOS ESTATÍSTICOS A PARTIR DA INTERSECCIONALIDADE ENTRE SEXO E RAÇA COM TEMÁTICAS DE UMA ANÁLISE SOCIOECONÔMICA}

do lugar da mulher negra na sociedade. Desta forma, entende-se a importância de uma atividade didática que possa refletir sobre a construção de uma proposta para o ensino e aprendizagem de análises de gráficos. Entre os autores utilizados para a análise desses gráficos estão Curcio (1987) e Monteiro (2006).

Por fim, entende-se a relevância deste artigo pela oportunidade de trazer visibilidade e protagonismo ao papel do negro, em particular da mulher negra, tema ainda pouco discutido nos espaços escolares. Além disso, busca-se fortalecer o legado economicamente produtivo e social da população negra, ainda pouco destacado, nas discussões estatísticas de diferentes espaços acadêmicos, sociais e políticos.

\section{A SOCIEDADE SUBALTERNA BRASILEIRA SOB A EXPLORAÇÃO DO TRABALHO}

Em 1943, com a era Vargas e a institucionalização da legislação trabalhista, a criação do teto para o salário mínimo se torna ponto positivo para a acumulação de bens, pois permite a estabilização do poder de compra do trabalhador, além de ser um impedimento para que os movimentos de operários organizados pressionem os setores da indústria com relação aos seus custos de produção. Caso se entenda a industrialização como a implantação do setor industrial, afirma-se que, antes da década de 1930, o país estava com esta demanda, vide a produção cafeeira nacional.

Também, pode-se conceituar a industrialização como sendo a "constituição de forças produtivas especificamente capitalistas" (TAVARES, 1998, p. 128). Neste caso, entende-se que este processo foi adiado para a década de 1950. Porém, ela combina dois elementos contraditórios no desenvolvimento econômico brasileiro. Um deles é o segmento urbano como determinante da realização dos lucros e o outro é a insuficiência da acumulação urbana para “implementar a grande indústria de base necessária ao crescimento da capacidade produtiva adiante da própria demanda" (TAVARES, 1998, p. 131).

A ideia da industrialização acelerada para o progresso social e a autonomia nacional do governo Vargas toma fôlego em 1956, quando Juscelino Kubitschek assume a presidência do Brasil e coloca em vigor o "Plano de Metas", criado pelo Conselho de Desenvolvimento, com 


\section{UMA PROPOSTA DE SEQUÊNCIA DIDÁTICA PARA ENSINO DE GRÁFICOS ESTATÍSTICOS A PARTIR DA INTERSECCIONALIDADE ENTRE SEXO E RAÇA COM TEMÁTICAS DE UMA ANÁLISE SOCIOECONÔMICA}

o slogan "50 anos em 5". A política adotada priorizou, também, os investimentos em infraestrutura de transportes, além da criação da Superintendência para o Desenvolvimento do Nordeste (SUDENE) e a construção da nova capital - Brasília. Para Lessa (1983, p. 27), “o Plano conferia prioridade absoluta à construção dos estágios superiores da pirâmide industrial verticalmente integrada e do capital social básico de apoio a esta estrutura".

Nos anos 1960, como aponta Medeiros (2016), houve um menor ritmo no crescimento populacional urbano e uma maior taxa de crescimento no emprego urbano. Para o autor, esta década foi um período de conflitos políticos, ideológicos e com mudanças institucionais. O período após a instauração do regime autoritário foi marcado pela "supressão da vida política democrática e a constituição de poderosos mecanismos de promoção da acumulação privada de capitais" (MEDEIROS, 2016, p. 126).

A dispersão dos salários estava fortemente condicionada pelo valor estipulado para o salário mínimo. Em condições de ampla heterogeneidade produtiva e descentralização das negociações, a queda do salário-mínimo real, especialmente acentuada a partir de 62, promoveu ampla diferenciação dos salários (MEDEIROS, 2016, p. 127).

Segundo a literatura (SERRA, 1975; LANGONI, 1978), durante os anos de 1960 a 1970 houve uma reconcentração de renda pessoal no Brasil e isto favoreceu o poder de consumo das classes burguesas. Sendo assim, a maior parte dos recursos que alimentaram o mercado financeiro corresponde a parcela de renda destas classes.

Destarte, o padrão de desenvolvimento que prevalece recai sobre a composição dos investimentos, a estrutura do consumo implícito, as formas e a dinâmica de dependência em relação ao exterior. Assim, a distribuição de renda aceitável passa a ser a que o sistema econômico produz.

O Brasil se destaca por ser um dos países que mais concentra renda, gerando um movimento contínuo de acúmulo de capital, com níveis crescentes de investimento que determinam os lucros e a poupança. Contudo, vale ressaltar que essas afirmações são referentes, apenas, ao comportamento do setor privado estrangeiro (marco das grandes empresas monopólicas estrangeiras), de modo que a poupança privada nacional e a pessoal apresentam pouco significado (SERRA, 1975, p.268). 


\section{UMA PROPOSTA DE SEQUÊNCIA DIDÁTICA PARA ENSINO DE GRÁFICOS ESTATÍSTICOS A PARTIR DA INTERSECCIONALIDADE ENTRE SEXO E RAÇA COM TEMÁTICAS DE UMA ANÁLISE SOCIOECONÔMICA}

Além disso, Langoni (1978) reverbera que o Brasil se constitui em um dos países que mais possui concentração de renda no mundo e ressalta as evidências de uma má distribuição de renda; autoconsumo do setor agrícola; uso de rendas correntes ao invés de renda permanente; diferença regional do custo de vida, bem como a variação de horas de trabalho. O autor também reforça que "os dados do Imposto de Renda confirmaram que a remuneração do capital físico (juros, lucros e aluguéis) é bem mais desigualmente distribuída do que a remuneração do capital humano (salários e ordenados)" (LANGONI, 1978, p. 206).

Sendo assim, há pessoas com alto poder aquisitivo que não dependem do trabalho para sobreviver, pois são oriundas de famílias que acumularam bens passados de geração a geração, não necessitam de nenhum sacrifício para continuar a investir e acumular lucros ou juros em um futuro próximo. Por outro lado, existem aqueles que dependem do trabalho para sobreviver e são privados de terem rendas acumuladas, em virtude desses bens concentrados nas mãos de poucas famílias ricas. Dito de outro modo, para continuar e manter a sua renda e obter lucros vantagens, seguindo do acúmulo de capital, a classe burguesa se vale da exploração das classes sociais não-privilegiadas, as quais produzem os bens e serviços. Com isto, ao permitir "aos ricos um padrão de vida luxuoso, [...] a distribuição desigual de renda é um método excessivamente antieconômico de se realizar a poupança necessária” (ROBINSON, 1942 apud SERRA, 1975, p. 270).

Ainda de acordo com Serra (1975), para que se tenha uma poupança determinada, é necessário que as classes ricas dissipem consideravelmente as rendas nas despesas ou gastos. Contudo, para as classes ricas não há uma preocupação com a justiça ou a injustiça social; existe apenas uma ordem econômica que responde aos critérios de eficiência.

Por outro lado, Serra (1975) salienta que a diferença da qualidade da mão de obra é um ponto fundamental para equiparar a injustiça social entre os assalariados. Langoni (1978) complementa que é preciso investir em recursos humanos (educação, migração e saúde), além de políticas agrícolas, tecnológicas e fiscais, maximizando seus serviços para o fator trabalho.

Para Serra (1975), a educação tem efeito sobre a distribuição de renda de dois modos: 1) derivado das desigualdades; e 2) derivado das imperfeições do mercado de trabalho. O autor declara que os níveis de renda e educação são correspondentes, contudo, "não se pode dizer que os desníveis educacionais são a causa dos desníveis de renda" (p. 273). Entretanto, 


\section{UMA PROPOSTA DE SEQUÊNCIA DIDÁTICA PARA ENSINO DE GRÁFICOS ESTATÍSTICOS A PARTIR DA INTERSECCIONALIDADE ENTRE SEXO E RAÇA COM TEMÁTICAS DE UMA ANÁLISE SOCIOECONÔMICA}

isoladamente, um indivíduo que possui uma melhor instrução tem a possibilidade de melhorar seu nível de renda. Deste modo, a melhora educacional, ainda que muito importante, neste contexto se apresenta somente como qualificação da mão de obra.

Como evidência dessa dualidade da relação educação versus concentração de renda, Serra (1975) aponta que categorias como professores, enfermeiros, agrônomos, veterinários, embora consideradas essenciais para o desenvolvimento social e econômico, têm um dos salários menos valorizados, o que se justifica em sua pouca procura. Mais especificamente sobre a categoria de professores, Serra (1975) acrescenta que os educadores do ensino secundário não solucionaram o problema da mão de obra qualificada, salvo se fosse através dos cursos técnicos.

Sobre formação qualificada, Langoni (1978) salienta que no setor primário, no período da década de 1960, a formação de mão de obra qualificada não era prioridade, e sim a faixa etária e as diferenças regionais de renda. Já no setor secundário, o crescimento considerável da empregabilidade entre 1961 a 1967 é ocasionado com a formação técnica e o ensino superior. “A educação torna-se um importante mecanismo de transmissão da influência do status familiar, sendo a variável mais importante na determinação da renda individual" (LANGONI, 1978, p. 209 - grifos do autor).

Nos dados do censo demográfico entre 1960 e 1970, “a renda total e média dessas classes (ao considerar raça e gênero) são precárias e podem conduzir a resultados que distorcem os graus de concentração" (SERRA, 1975, p. 279). No entanto, Langoni (1978) salienta que a desigualdade social na década de 1970 era evidenciada, sobretudo, por uma má perspectiva para analfabetos, trabalhadores rurais e para indivíduos que estavam localizados na região nordeste do Brasil. Por fim, a educação se apresenta como peça-chave tanto na explicação sobre os níveis de distribuição de renda, como nos impactos sociais e econômicos da má qualificação da mão de obra. Entretanto, como justificado por Serra (1975), o nível educacional não é a causa determinante dos desacertos econômicos.

Apoiando-se em Langoni (1978) e Medeiros (2016), reflete-se sobre os critérios de remuneração utilizados no período de industrialização no país e se há, dentro do modelo capitalista, uma necessidade de baixa qualificação para manutenção do lucro dos detentores dos meios de produção no Brasil. Por outro lado, havia a necessidade da qualificação dos 


\section{UMA PROPOSTA DE SEQUÊNCIA DIDÁTICA PARA ENSINO DE GRÁFICOS ESTATÍSTICOS A PARTIR DA INTERSECCIONALIDADE ENTRE SEXO E RAÇA COM TEMÁTICAS DE UMA ANÁLISE SOCIOECONÔMICA}

trabalhadores para a continuidade e qualidade da produção. Há, então, uma dualidade entre produção de bens de consumo e produção de material humano para produção destes bens.

Nesta perspectiva, a educação se torna um caminho importante de justiça social contra a desigualdade e a hierarquia social. Contudo, o direito à educação por muito tempo sempre foi negado ou bastante restrito para a população pobre, principalmente a negra. Segundo Andrews (2015), em 1950, 5\% da população branca completou o ensino médio, enquanto, referente à população negra, esse número foi de apenas 0,5\%. Embora durante o regime militar (entre 1964 e 1985) o governo tenha investido na educação superior, há uma pequena parcela da população brasileira branca que teve acesso. No ano de 1987, a estatística de negros, pardos e brancos nas universidades era de $1 \%, 2 \%$ e $9 \%$, respectivamente.

A partir de 1994, o governo brasileiro começa a se preocupar com as questões sobre desigualdade social, racial e distribuição de renda. Inicialmente com a implantação do plano real e o aumento do salário mínimo entre os anos de 1994 e 2009, dando ao trabalhador poder de compra. Com isto, "entre as décadas de 90 e 00, a taxa de pobreza reduziu-se pela metade, bem como seu índice de Gini, ${ }^{\text {iii }}$ referente à concentração de renda que reduz de 61 para 54" (ANDREWS, 2015, p. 147-148). Também se destaca, em 2012, a implantação da Lei no 12.711, em que defende as políticas de ações afirmativas com fins de garantir aos alunos oriundos de escolas públicas acesso a 50\% das vagas às Instituições Federais de Ensino Superior e, dentro deste percentual, metade dessas vagas é disputada por estudantes com renda familiar abaixo de 1,5 salário mínimo. A partir da Lei no 13.409/2016, o percentual de cotas passa a ser garantido também para estudantes autodeclarados pretos, pardos e indígenas, sendo contabilizadas o número de vagas de acordo ao quantitativo do censo demográfico em cada região, numa tentativa de reparação da dívida histórica frente às desigualdades socioeconômicas e educacionais entre negros e brancos.

Vale ressaltar que, embora haja benefícios que levem a população negra e pobre a acreditar que poderá ter uma condição de vida digna, ainda há lutas a serem travadas para diminuir a desigualdade social, em particular, o racismo estrutural. Mesmo a população negra sendo maior do que a branca no país, é comum identificar cargos de chefias, com os melhores salários, com a população branca. Informações como estas se tornam mais evidentes quando se trata da mulher pobre e negra.

\begin{tabular}{l|l} 
Revista RBBA & Revista Binacional Brasil Argentina
\end{tabular} 


\section{UMA PROPOSTA DE SEQUÊNCIA DIDÁTICA PARA ENSINO DE GRÁFICOS ESTATÍSTICOS A PARTIR DA INTERSECCIONALIDADE ENTRE SEXO E RAÇA COM TEMÁTICAS DE UMA ANÁLISE SOCIOECONÔMICA}

\section{O LUGAR DAS MULHERES NEGRAS EM UMA SOCIEDADE CAPITALISTA}

A desigualdade de renda entre sexo e raça ainda está muito presente no Brasil, sobretudo para as mulheres negras que continuam abaixo da pirâmide de salários e oportunidades de emprego. Para Matos e Machado (2006), a partir de 1979, mesmo as mulheres passando a ter mais anos de escolaridade do que os homens, a variável gênero continua sendo motivo de desigualdade salarial.

Assim sendo, Soares (2000, p. 5) complementa que "a discriminação nas sociedades humanas é prática tão disseminada quanto nefasta. Onde existe a diferença, existem indivíduos cujas vidas são prejudicadas por pertencerem a um ou outro grupo que foge a determinadas normas”. Em particular, no Brasil, a discriminação ocorre em uma sociedade machista, misógina e racista, a qual necessita fortalecer as relações de poder baseadas nos discursos de gênero e raça para imperar a lógica da exploração do trabalho e subalternidade. Em tempos mais recentes, este fator discriminatório, principalmente sobre a mulher negra, ainda está muito presente no país.

No Brasil, a desigualdade de raça não é um fenômeno que abrange uma "minoria", pelo contrário, abrange grande parte da população, já que em 2003, os negros (de ambos os sexos) representavam $46 \%$ da População Economicamente Ativa, e as mulheres negras correspondiam a $18 \%$ da PEA, recebendo uma dupla discriminação (de gênero e de raça). Portanto, as mulheres negras apresentam desvantagem em todos os principais indicadores sociais e de mercado de trabalho (CASTRO; STAMM, 2016, p. 6 - grifo dos autores).

Desse modo, a interseccionalidade entre raça e sexo se configura economicamente como um verdadeiro impacto na desigualdade social. Castro e Stamm (2016) reverberam o que já está posto na literatura quanto ao lugar da população negra no mercado de trabalho, ou seja, com menos oportunidade de educação formal básica e superior, a desigualdade salarial contribui de forma racista e discriminatória para a ascensão social desses indivíduos. Em 2019, quanto à situação das mulheres negras frente a pirâmide dos homens brancos e negros e das mulheres brancas, constatou-se que, embora haja uma desigualdade de gênero, não se estabelece esclarecimentos da igualdade de raça e cita-se um exemplo: "mulheres ganham $30 \%$ a menos do que homens no Brasil”' (RIBEIRO, 2019, p. 39). 


\section{UMA PROPOSTA DE SEQUÊNCIA DIDÁTICA PARA ENSINO DE GRÁFICOS ESTATÍSTICOS A PARTIR DA INTERSECCIONALIDADE ENTRE SEXO E RAÇA COM TEMÁTICAS DE UMA ANÁLISE SOCIOECONÔMICA}

Analisando sites como do IBGE, isto é bastante comum, pois há explicitamente um esclarecimento dos dados estatísticos sobre os números pesquisados considerando comparações entre gêneros, acerca das estruturas econômicas e a participação em atividades produtivas. Contudo, Ribeiro (2019, p. 39-40) reitera que esse exemplo não deixa explícito o que está sendo posto na pirâmide do censo demográfico, ou seja, que "homens negros ganham menos do que mulheres brancas e mulheres negras ganham menos do que todos". Para tanto, a autora se respalda em pesquisas desenvolvidas pelo Instituto de Pesquisa Econômica Aplicada (IPEA), realizadas em 2016, para ressaltar que as mulheres negras "eram o maior contingente de pessoas desempregadas e no trabalho doméstico" (RIBEIRO, 2019, p. 40).

Marx postulava que, por mais desarticulados e incipientes, os grupos
oprimidos possuíam um ponto de vista particular sobre as desigualdades. Em
versão mais contemporânea, a desigualdade foi revisada para refletir um maior
grau de complexidade, especialmente de raça e gênero. O que temos agora é
uma crescente sofisticação sobre como discutir localização de grupo, não o
quadro singular de Marx [...], mas dentro de uma construção múltiplas
residentes nas próprias estruturas sociais [...] (COLLINS, 1997, p. 9).

O avanço do capitalismo corrobora com a intensificação da inferioridade feminina. Assim tem-se o aumento da participação da mulher na dinâmica industrial e a sua diminuição das rotinas domésticas de cuidado e manutenção da ordem. Destaca-se que esta diminuição não deveria ser considerada deste modo, já que historicamente o lugar da mulher parecia ser efetivamente dentro do lar. Previamente a industrialização, as mulheres estavam presentes em casa, de maneira tal que se a economia estava centrada no cultivo de terras, elas frequentemente ajudavam os seus maridos na lavoura, ou seja, não abdicaram do seu papel de trabalhadoras, apenas estavam restritas ao ambiente doméstico.

A partir disso, reflete-se que essas medidas são muito injustas ao público feminino e o legado foi o da subalternação e condição de inferioridade ideológica, sendo, portanto, o problema do sexismo aliado ao racismo, a aniquilação da existência da mulher negra, alocandoa a animalidade. Com isto, pretende-se permitir ao leitor ou a leitora uma visão concisa de uma parte que nos falta da história: o papel da mulher e com ênfase na mulher negra, na construção de sua história e a sua resistência às condições de rebaixamento ao patriarcado. 


\section{UMA PROPOSTA DE SEQUÊNCIA DIDÁTICA PARA ENSINO DE GRÁFICOS ESTATÍSTICOS A PARTIR DA INTERSECCIONALIDADE ENTRE SEXO E RAÇA COM TEMÁTICAS DE UMA ANÁLISE SOCIOECONÔMICA}

Entende-se que compreender esta conjuntura apresentada a partir dos dados estatísticos pode contribuir para maiores reflexões às questões aqui levantadas. Isto será abordado no contexto educacional.

\section{LETRAMENTO ESTATÍSTICO E INTERPRETAÇÃO DE GRÁFICOS}

A Estatística pode ser entendida, de modo bem sintético, como número em um contexto de situações de incerteza. No século XX, ela foi incorporada à pesquisa empírica e científica, a partir do método estatístico, que envolve coleta, organização e análise de dados. Assim, institutos e órgãos de pesquisas oficiais realizam investigações para "subsidiar decisões políticas, econômicas e sociais dos países" (CAZORLA; KATAOKA; SILVA, 2010, p. 19). Nestas pesquisas, os dados coletados são apresentados e interpretados a partir de mapas, tabelas e gráficos estatísticos. Com isto, os dados se transformam em informações, pois são organizados e analisados. "Isso implica que a informação possuirá o filtro de quem gera a informação, ou seja, ela não é neutra" (CAZORLA; OLIVEIRA, 2010, p. 119).

É necessário, portanto, interpretar estas informações, ou seja, mobilizar ações como ouvir, ler, ver, resumir internamente, comparar, conectar e traduzir (WILD; PFANNKUCH, 1999). No contexto educacional, a Educação Estatística pode contribuir com este processo e



Segundo Gal (2002), o letramento estatístico é tido como uma das competências estatísticas e pode ser compreendido a partir de dois aspectos relacionados à capacidade de: (a) interpretar e avaliar criticamente as informações estatísticas e os argumentos utilizados [...] em diversos contextos, incluindo os meios de comunicação, mas não se limitando a eles; e (b) discutir e comunicar suas opiniões a respeito das informações estatísticas, como na compreensão dos significados, suas implicações e sobre a aceitação das conclusões apresentadas. 


\section{UMA PROPOSTA DE SEQUÊNCIA DIDÁTICA PARA ENSINO DE GRÁFICOS ESTATÍSTICOS A PARTIR DA INTERSECCIONALIDADE ENTRE SEXO E RAÇA COM TEMÁTICAS DE UMA ANÁLISE SOCIOECONÔMICA}

Ao abordar o letramento estatístico, Watson (2006, p. 6 apud. ALMEIDA, 2018, p. 625) o considera

[...] no sentido essencial de promover uma ampliação baseada no currículo de matemática para todos os alunos utilizarem quando deixarem a escola e começarem a fazer parte da sociedade como cidadãos conscientes. Além disso, é necessário promover uma base para o desenvolvimento do entendimento formal estatístico para os alunos que escolherem avançar em cursos secundários e superiores.

O letramento estatístico pressupõe que se deve ter familiaridade com conceitos e ideias básicos da estatística, incluindo as representações gráficas e tabulares (GAL, 2002). Neste sentido, este artigo propõe atividades baseadas na resolução de problemas, uma vez que o aluno se deparará com questões que, a priori, ele não sabe a resposta (PONTE; BROCARDO; OLIVEIRA, 2003).

O foco das atividades é a interpretação de gráficos estatísticos, partindo de dados coletados em órgãos e institutos governamentais do Brasil. Os gráficos estatísticos são tidos como uma forma de comunicação escrita, ou seja, um texto (CURCIO, 1987). Para isto, os conhecimentos prévios dos alunos são importantes e podem incluir os matemáticos e de experiências prévias acerca do tema da realidade investigada (MONTEIRO, 2006).

Assim, no processo de interpretação de gráficos estatísticos, há elementos que podem ser relacionados, mas que são de naturezas distintas. Curcio (1987) destaca a necessidade de reconhecer o tipo de gráfico, as relações matemáticas que existem entre os números e as operações e, assim, argumenta que há três níveis de compreensão dos gráficos estatísticos.

No primeiro nível, ler os dados, identificam-se dados pontuais apresentados, como uma informação de um valor correspondente a um ano. O segundo nível, ler entre os dados, precisase comparar ou combinar os dados, como na identificação do valor máximo de uma variável. Já no terceiro nível, ler além dos dados, os alunos extrapolam os dados apresentados no gráfico, predizendo resultados (CURCIO, 1987).

Monteiro (2006), dentre outros autores, sinalizou que há outros aspectos não contemplados por Curcio (1987) que podem emergir na interpretação dos gráficos estatísticos. Diniz (2016) renomeia este processo de aspectos socioculturais para enfatizar os elementos diferentes dos conhecimentos matemáticos, acrescentando o último elemento (listado abaixo), 


\section{UMA PROPOSTA DE SEQUÊNCIA DIDÁTICA PARA ENSINO DE GRÁFICOS ESTATÍSTICOS A PARTIR DA INTERSECCIONALIDADE ENTRE SEXO E RAÇA COM TEMÁTICAS DE UMA ANÁLISE SOCIOECONÔMICA}

baseado em D’Ambrosio (2004), à classificação inicialmente elaborada por Monteiro (2006). Assim, no processo de interpretação dos gráficos, as pessoas podem mobilizar:

a) a referência contextual: conhecimentos do contexto social, político e/ou econômico;

b) a expressão afetiva: sentimentos e emoções;

c) a exemplificação pessoal: experiências anteriores e pessoais;

d) o conhecimento etnomatemático: manifestações matemáticas diferentes da matemática escolar (formal), ou seja, diferentes formas de medir, comparar, classificar etc., que são impregnadas de elementos culturais.

A seguir, as atividades propostas serão apresentadas e analisadas a partir das características apontadas por Curcio (1987), Monteiro (2006) e do letramento estatístico.

\section{APRESENTAÇÃO E DISCUSSÃO DAS ATIVIDADES PROPOSTAS}

As atividades foram elaboradas para serem trabalhadas em turmas do Ensino Médio, sendo os alunos reunidos em grupos de até quatro membros, de modo a resolverem os problemas propostos, mediante orientação do (a) professor (a). Shulman (1986) nomeia estas atividades de Caso de Ensino, que é uma proposta a ser discutida coletivamente a ser refletida teoricamente. Segundo o autor, o docente deve conhecer o conteúdo a ser abordado em diferentes ambientes de aprendizagem que podem contribuir para a aprendizagem dos alunos. Por isto, Shulman (1986) entende que um Caso de Ensino deve ser debatido, explicado, analisado e remontado.

Os grupos receberão as atividades do Caso de Ensino contendo os gráficos estatísticos, os quais foram construídos a partir das Pesquisas de Emprego e Desemprego (PED) do Instituto Brasileiro de Geografia e Estatística (IBGE) e do Departamento Intersindical de Estatística e Estudos Socioeconômicos (DIEESE), entre os anos de 2011 e 2017. Os gráficos abordam os assuntos População Economicamente Ativa (PEA), renda e educação de trabalhadores (as), considerando gênero e raça/cor. ${ }^{\text {iv }}$

A análise sobre a discriminação e o preconceito acerca da raça/cor negra e não-negra, em aspectos socioeconômicos, será abordada sob a ótica dos dados estatísticos das populações de Salvador-BA e São Paulo-SP, conforme justificado na introdução. Contudo, os dados educacionais não foram encontrados apenas nas cidades mencionadas, optando-se pelos dados 


\section{UMA PROPOSTA DE SEQUÊNCIA DIDÁTICA PARA ENSINO DE GRÁFICOS ESTATÍSTICOS A PARTIR DA INTERSECCIONALIDADE ENTRE SEXO E RAÇA COM TEMÁTICAS DE UMA ANÁLISE SOCIOECONÔMICA}

das regiões do Brasil onde estas cidades estão localizadas, isto é, região Nordeste e Sudeste, pois as cidades estão entre as mais importantes, em vários aspectos, de cada região mencionada.

Em cada atividade, as questões buscaram atender pelo menos dois dos níveis de Curcio (1987) e, quando possível, ao senso crítico de Monteiro (2006). Assim, o foco central são as reflexões críticas que os estudantes deverão realizar buscando comparar as informações presentes nos gráficos, considerando os aspectos socioeconômicos sobre a interseccionalidade entre raça/cor e sexo.

Atividade 1: Considere que a População Economicamente Ativa (PEA) é um conceito para designar a população que está inserida no mercado de trabalho para exercer uma atividade remunerada.

Gráfico 1 - População Economicamente Ativa em Salvador-BA

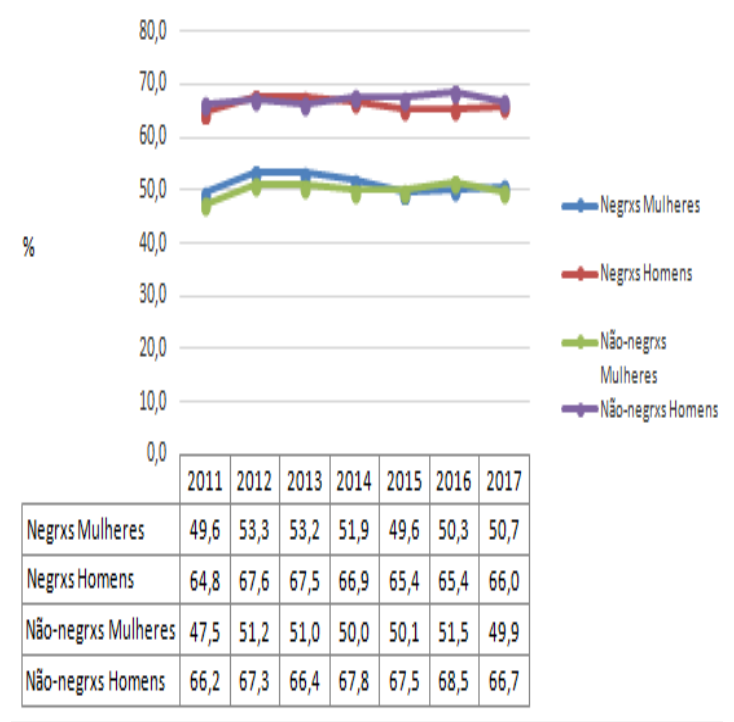

Gráfico 2 - População Economicamente Ativa em São Paulo-SP

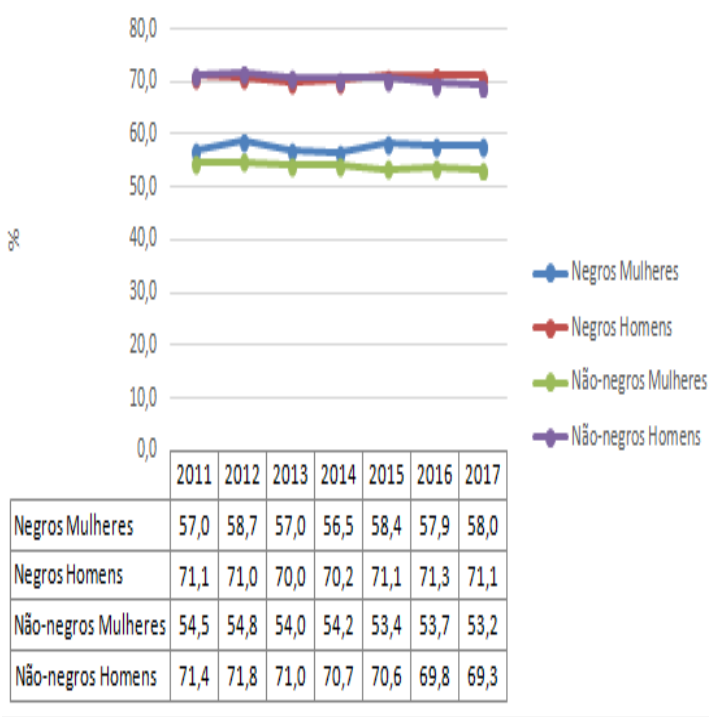

Fonte: PED-Região Metropolitana de Salvador e São Paulo - Convênio SEI, Setre, Dieese, Seade, MTb/FAT.

Para responder as questões, considerem que os gráficos 1 e 2.

a) Quantos por cento de mulheres negras eram da PEA em Salvador e São Paulo?

b) Comparando os dados de 2016, você percebe diferenças entre mulheres negras e não-negras? Comente considerando cada cidade.

c) Comparando homens e mulheres, por que o percentual dos homens é superior ao das mulheres nas duas cidades? 


\section{UMA PROPOSTA DE SEQUÊNCIA DIDÁTICA PARA ENSINO DE GRÁFICOS ESTATÍSTICOS A PARTIR DA INTERSECCIONALIDADE ENTRE SEXO E RAÇA COM TEMÁTICAS DE UMA ANÁLISE SOCIOECONÔMICA}

Esta questão é proposta com o objetivo de comparar sexo e raça/cor nas duas capitais, no período mencionado. No item a, contemplou-se a leitura do dado e nos itens b e c, destacouse a leitura entre os dados, de modo que, inicialmente, enfatizou-se a diferença entre as mulheres e, posteriormente, entre os sexos (CURCIO, 1987). Com isto, buscou-se ressaltar a análise crítica sobre a condição do homem negro e da mulher negra na sociedade. Neste sentido, considerar a discussão do sexo e da raça/cor, para além de justificar estudos acerca da inferioridade do (a) negro (a), é considerado como um fator que pode promover e justificar a imensa desigualdade econômica. Por isso que toda e qualquer ação de combate ao racismo, que não a considere, não será efetiva (LIMA, 2010).

Neste sentido, autores como Batista e Mastrodi (2018) e Batista (2018) defendem que mesmo que a população negra tenha ascensão social, ela ainda perdura em ataques racistas que se diferenciam apenas na forma de violência e estrutura para a cultura. Com isso, manter a reprodução do racismo no imaginário nacional é uma forma de atender aos interesses de uma elite de dominação da exploração e supremacia social. Assim, o "apego ao passado escravagista e a um anacrônico ideal de supremacia branca desta elite" (BATISTA, 2018, p. 2584) se mantém para continuar a concentração de renda e do favorecimento do poder de consumo das classes burguesas (SERRA, 1975; LANGONI, 1978).

Assim, pode-se identificar a possibilidade da exemplificação pessoal e referência contextual (MONTEIRO, 2006), uma vez que os estudantes podem mobilizar experiências anteriores e pessoais sobre o tema dos gráficos, além dos sentimentos e emoções.

Na questão 2, o objetivo é analisar o salário médio nas duas cidades no período de 2011 a 2017, com a intenção de comparar a situação socioeconômica das mulheres negras e brancas e dos homens negros e brancos no setor privado, já que a renda é a mesma para todos (as) os (as) servidores públicos (as) que exercem a mesma função. Além disto, foi proposta a análise da amplitude salarial média das cidades, considerando a mulher negra e o grupo com a maior amplitude, o qual teve maior decréscimo salarial acerca da desigualdade social, sobretudo racial, no que tange os grupos analisados. Este é um dos aspectos que articulam as discussões propostas por Monteiro (2006) e Curcio (1987), sendo este último com questões contempladas nos três níveis de compreensão dos gráficos estatísticos. 
UMA PROPOSTA DE SEQUÊNCIA DIDÁTICA PARA ENSINO DE GRÁFICOS ESTATÍSTICOS A PARTIR DA INTERSECCIONALIDADE ENTRE SEXO E RAÇA COM TEMÁTICAS DE UMA ANÁLISE SOCIOECONÔMICA

Atividade 2: Considerem a média salarial no setor privado, considerando gênero e raça nas cidades de Salvador e São Paulo.

Gráfico 3 - Média Salarial no Setor Privado (gênero e raça) em Salvador-BA

$\rightarrow$ Negrxs Mulheres $\rightarrow$ NegrxsHomens $\rightarrow$ Não-negrrx Mulheres $\rightarrow$ Não-negrxs Homens

3.500

3.000

2.500

2.000

1.500

1.000

500

\begin{tabular}{|c|c|c|c|c|c|c|c|}
\hline 0 & 2011 & 2012 & 2013 & 2014 & 2015 & 2016 & 2017 \\
\hline Negrxs Mulheres & 1.310 & 1.304 & 1.302 & 1.339 & 1.328 & 1.277 & 1.306 \\
\hline Negrxs Homens & 1.610 & 1.559 & 1.615 & 1.626 & 1.572 & 1.432 & 1.466 \\
\hline Não-negrxs Mulheres & 1.881 & 1.895 & 1.866 & 1.826 & 1.549 & & \\
\hline Näo-negrxs Homens & 2.227 & 2.341 & 2.345 & 2.366 & 1.900 & 1.730 & 1.744 \\
\hline
\end{tabular}

Gráfico 4 - Média Salarial no Setor Privado (gênero e raça) em São Paulo-SP

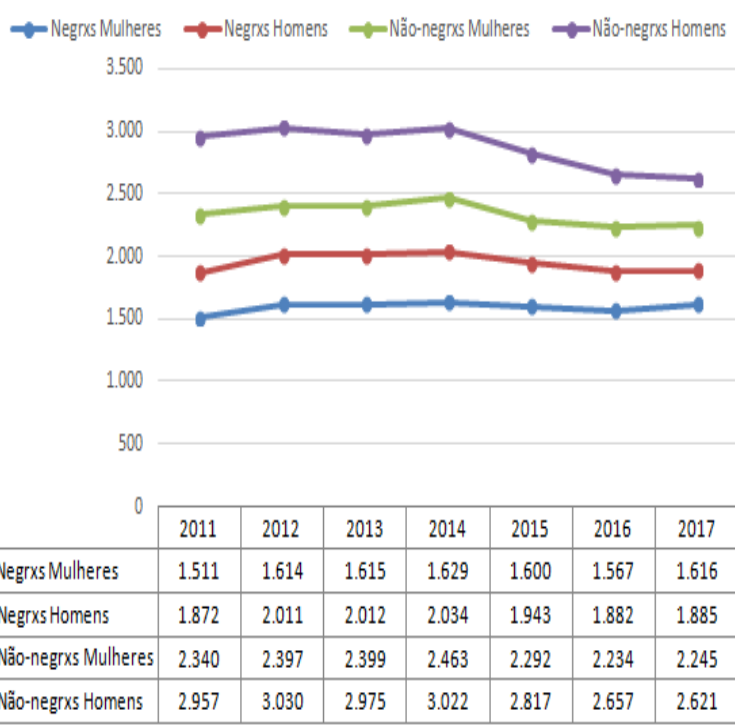

Fonte: PED-Região Metropolitana de Salvador e São Paulo - Convênio SEI, Setre, Dieese, Seade, MTb/FAT.

A amostra não apresenta resultados para a categoria mulheres não-negros (as) em 2016 e 2017.

a) Qual é o salário médio da mulher negra das cidades no ano de 2015 ?

b) Comparando os valores encontrados no item a, qual das cidades tem a maior renda e quanto é a diferença entre os valores? Como explicam esta diferença?

c) Calcule a diferença entre os valores máximo e mínimo, no período de 2011 a 2017, das médias salariais para o homem não-negro e a mulher negra em cada cidade. A isto se denomina amplitude. Assim, analisem os valores obtidos.

d) O gráfico da média salarial em Salvador não tem os dados de mulheres não-negras em 2016 e 2017. Estimem estes valores, por hipótese. Justifiquem os valores que escolheram.

Pode-se perceber que, para a mulher negra, em ambas as cidades houve um pequeno acréscimo salarial no intervalo analisado. Já para o homem não-negro, no mesmo período, houve um decréscimo. Isto pode ser justificado, em parte, devido ao aumento do acesso da mulher negra ao ensino médio e superior, o que será aprofundado na próxima atividade. 


\section{UMA PROPOSTA DE SEQUÊNCIA DIDÁTICA PARA ENSINO DE GRÁFICOS ESTATÍSTICOS A PARTIR DA INTERSECCIONALIDADE ENTRE SEXO E RAÇA COM TEMÁTICAS DE UMA ANÁLISE SOCIOECONÔMICA}

Destarte, é possível destacar que essa atividade apresenta as consequências do racismo estrutural ao ignorar a produção intelectual de mulheres negras no mercado de trabalho, ainda que sua formação profissional the permita uma condição salarial equiparada ao do homem negro. Segundo Barreto (2017), as condições de igualdade socioeconômicas, asseguradas legalmente à população negra, não foram garantidas, isto é, ainda impera o racismo, a desigualdade e a marginalização mantidos por uma classe burguesa que mantém um acúmulo de capital, valendo-se da exploração e dos não-privilégios dessas classes que, sob regime "trabalhista", produzem os bens e prestam serviços (SERRA, 1975).

A questão 3 objetiva relacionar educação e renda. Parte-se do pressuposto de que a educação é condição para que as pessoas melhorem suas rendas e isto será percebido a partir das taxas de conclusão dos ensinos médio e superior. Pode-se perceber que os homens negros são os que possuem as menores taxas de conclusão e as mulheres negras têm as menores médias salariais. As questões contemplam os níveis 1 e 2 de Curcio (1987) e a exemplificação pessoal e referência contextual de Monteiro (2006).

Atividade 3: Agora, tem-se os dados da taxa de conclusão do ensino superior nas regiões Nordeste e Sudeste do Brasil, considerando gênero e raça, no período de 2012 a 2016.

Gráfico 5 - Taxa de conclusão do ensino superior, por sexo, segundo raça/cor na região Nordeste do Brasil

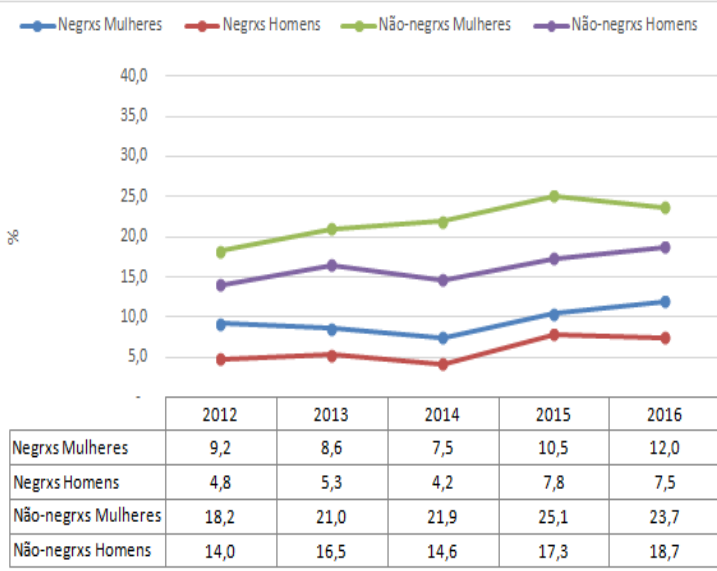

Gráfico 6 - Taxa de conclusão do ensino superior, por sexo, segundo raça/cor na região Sudeste do Brasil



Fonte: IBGE. Pesquisa Nacional por Amostra de Domicílios Contínua, 2012 a 2016, segundo trimestre. 


\section{UMA PROPOSTA DE SEQUÊNCIA DIDÁTICA PARA ENSINO DE GRÁFICOS ESTATÍSTICOS A PARTIR DA INTERSECCIONALIDADE ENTRE SEXO E RAÇA COM TEMÁTICAS DE UMA ANÁLISE SOCIOECONÔMICA}

a) Qual é a taxa de conclusão do ensino médio das mulheres negras em 2015 nas regiões nordeste e sudeste?

b) Comparando os valores encontrados no item a, qual das cidades tem a maior taxa de conclusão do ensino médio e quanto é a diferença entre os valores? Como explicam esta diferença?

c) Segundo Langoni (1978, p. 209), “A educação torna-se um importante mecanismo de transmissão da influência do status familiar, sendo a variável mais importante na determinação da renda familiar". Assim, comparem os gráficos da questão 2 com os da questão 3 e analisem, conforme a afirmação de Langoni para a mulher negra. Comentem as conclusões que obtiveram.

d) Considerando os dados da Taxa de Conclusão do Ensino Médio para o ano de 2016, conforme o Quadro 1, escrevam interpretações para estes dados, comparando-os com os gráficos estatísticos, com foco nas mulheres negras.

Quadro 1 - Taxa de Conclusão do Ensino Médio, por sexo, segundo raça/cor nas regiões Nordeste e Sudeste em 2016

\begin{tabular}{|l|c|c|c|c|}
\hline & \multicolumn{2}{|c|}{ Negros (as) } & \multicolumn{2}{c|}{ Não-negros (as) } \\
\hline & Mulheres & Homens & Mulheres & Homens \\
\hline Nordeste & 61,6 & 47,3 & 75,1 & 59,4 \\
\hline Sudeste & 72,1 & 57,6 & 84,4 & 77,8 \\
\hline
\end{tabular}

Fonte: IBGE. Pesquisa Nacional por Amostra de Domicílios Contínua, 2016, segundo trimestre.

Sobre os dados apresentados na seção 2 desta pesquisa, reitera-se o que já foi pontuado sobre a interseccionalidade de sexo e raça/cor, no tocante às questões socioeconômicas. A constituição do país como um dos que mais possui concentração de renda, especificamente com má distribuição de renda, a diferença regional do custo de vida e a variação de horas de trabalho reforçam que o capital físico é mais desigual na sua distribuição do que a remuneração do capital humano.

No entanto, considerando as questões interseccionais discutidas nesta atividade, a remuneração do capital humano, quando comparada a questão de sexo e raça/cor, apresenta-se com evidente desigualdade no que tange a remuneração deste mesmo capital. Para diminuir esse distanciamento da grande concentração de renda na mão de poucos, Serra (1975) salienta como ponto fundamental para equiparar a injustiça social entre os assalariados a diferença da qualidade da mão de obra. Langoni (1978) complementa que é preciso investir em recursos humanos (educação, migração e saúde). Além disso, acrescenta-se que o racismo também se 


\section{UMA PROPOSTA DE SEQUÊNCIA DIDÁTICA PARA ENSINO DE GRÁFICOS ESTATÍSTICOS A PARTIR DA INTERSECCIONALIDADE ENTRE SEXO E RAÇA COM TEMÁTICAS DE UMA ANÁLISE SOCIOECONÔMICA}

configura como um dos motivos da manutenção desta concentração de renda considerando que, mesmo após o "fim da escravidão", evidencia-se que ainda há racismo na sociedade brasileira atualmente (BATISTA; MASTRODI, 2018).

Portanto, é perceptível o quanto os (as) negros (as) continuam subalternos no sistema escravista por forças não-econômicas, em "uma exploração dupla: o sistema econômico se aproveita do sistema social racista para negociar a força de trabalho do negro no mercado de trabalho, sendo ainda mais barata quando equiparada ao da mulher negra, mesmo com crescimento e melhoria de escolaridade” (BATISTA; MASTRODI, 2018, p. 2335).

\section{CONSIDERAÇÕES FINAIS}

Discutir sobre aspectos socioeconômicos de sexo e raça/cor ainda é um desafio, visto que os institutos e órgãos de pesquisa apresentam esses dados de forma limitada, principalmente com os dados para pretos e pardos, uma vez que consideram negros e pardos como raça negra. Além disso, o tema se torna ainda "mais caro" ao ser comparado com o grau de escolaridade na especificidade entre raça/cor e sexo por cidade, pois, ao fazer buscas na Internet, foi possível encontrar os dados estatísticos por raça/cor ou por sexo, mas raramente com ambos, o que revela a primeira dificuldade na construção desta proposta. Contudo, a partir dos dados que podem ser encontrados em sites do IBGE, DIEESE e PED, elaborou-se questões para a proposição de reflexões sobre a interseccionalidade entre raça/cor e sexo, fazendo um recorte em aspectos relacionados às questões socioeconômicas.

Entende-se que a relevância dessa temática para alunos (as) de escola pública está em compreender que a desigualdade social ainda persiste e que a educação pode ser um caminho para o enfrentamento dessa desigualdade. Além disso, essas discussões também se tornam pertinentes para que este (a) cidadão (ã) negro (a) saiba que é dever do Estado promover o fortalecimento das políticas públicas e ações afirmativas para a garantia de equidade de direitos para a população negra no contexto socioeconômico e cultural do Brasil.

Destarte, considera-se que o estado tem grande influência sobre as oportunidades de equidade para os (as) pobres, brancos (as) e negros (as) e, especialmente, a mulher pobre e negra, a qual precisa ser discutida, não como um aspecto meritocrático, mas sob o olhar de 


\section{UMA PROPOSTA DE SEQUÊNCIA DIDÁTICA PARA ENSINO DE GRÁFICOS ESTATÍSTICOS A PARTIR DA INTERSECCIONALIDADE ENTRE SEXO E RAÇA COM TEMÁTICAS DE UMA ANÁLISE SOCIOECONÔMICA}

cidadã, que necessita ter visibilidade por parte do poder público. Este, por sua vez, não pode se eximir de sua responsabilidade constitucional de assegurar direitos para todos (as), sem distinção. Salienta-se que a pouca representatividade no poder impede que a mulher negra conquiste o respeito e a equidade de direito, persistindo o racismo estrutural na negação a sua presença em diferentes espaços da sociedade, como cargos de chefias, protagonismos nas produções científicas e tecnológicas, no acesso a educação básica e superior, enfim, em lugar de destaque, como se pode perceber nos gráficos sobre educação e média salarial. Esses espaços só serão conquistados quando for asseverado, de fato, o direito aos estudos para adquirir uma boa formação profissional e, assim, competir em "pé de igualdade" no mercado de trabalho, continuando a luta contra a desigualdade social, em especial quando se trata de racismo estrutural.

Mesmo com a institucionalização de leis, o racismo estrutural, velado, sutil e, às vezes explícito, tenta impedir os (as) negros (as) de competirem no mercado de trabalho, mesmo tendo uma boa escolaridade e competência profissional, o que se traduz na limitação deste artigo, cujos dados não permitiram maior aprofundamento, propondo-se, como nova sugestão de atividade, a análise da média salarial dos (as) empregados (as) domésticos (as). Além disto, o racismo se reverbera quando há o confrontamento com estatísticas recentes, como o genocídio negro (a) e o feminicídio das mulheres negras, evidenciando-se, deste modo, a perseguição ao povo negro ainda existe, sendo que a questão também pode ser discutida por meio de atividades. Isto destaca, infelizmente, a vulnerabilidade da população negra, que além de buscar direitos básicos, como o acesso aos estudos, necessita também lutar pelo direito à sobrevivência e proteção à vida.

Aqui, preferiu-se focar em aspectos da legitimação da força de trabalho da mulher negra, levando em conta, para tal, a escolaridade e a polarização de setores de trabalho considerados restritos a ela, como o setor privado. Essa polarização foi importante para apresentar o quanto ainda há desigualdade e exploração de mão de obra salarial, junto ao mercado de trabalho, sobre a condição da mulher negra.

Por isto, entende-se que a sequência das atividades propostas foi elaborada com foco na interpretação de elementos teóricos apresentados na revisão de literatura deste artigo. Assim, 


\section{UMA PROPOSTA DE SEQUÊNCIA DIDÁTICA PARA ENSINO DE GRÁFICOS ESTATÍSTICOS A PARTIR DA INTERSECCIONALIDADE ENTRE SEXO E RAÇA COM TEMÁTICAS DE UMA ANÁLISE SOCIOECONÔMICA}

articulou-se com a interpretação dos gráficos estatísticos, uma vez que os órgãos e institutos governamentais fazem as pesquisas estatísticas considerando sexo e raça/cor.

Com isto, além da dificuldade já mencionada sobre o fato de ter acesso a dados sobre sexo e raça/cor conjuntamente, atender aos níveis de Curcio (1987) e aos aspectos socioculturais, propostos por Monteiro (2006) e Diniz (2016), corresponde a um segundo desafio. Assim, entende-se a relevância desta proposta por PEA, salário médio e educação, evidenciando o que já era um certo consenso: o quanto a educação pode "pesar" na renda e o quanto as mulheres, principalmente as negras, ainda sofrem com os preconceitos. Lançar luzes sobre isto em ambientes de escolas públicas faz com que se estabeleça uma "intimidade" entre saberes curriculares e a experiência social dos (as) estudantes, o que pode incluir saberes da etnomatemática, que são parte da cultura deles (as) (D’AMBROSIO, 2004). Isto é, também, um desafio no relacionar variáveis, que inicialmente não estavam articuladas.

Com isso, o (a) estudante tem a oportunidade de interpretar e opinar a respeito das informações, podendo colocá-las sob juízo, analisar suas implicações e aceitar ou não as conclusões propostas: operacionalizar o letramento estatístico (GAL, 2002). Assim, o ensino e a aprendizagem da estatística assume um papel crítico, pois sua abordagem oferece ferramentas para se (re)pensar a justiça social, o que também permite refletir sobre o papel da estatística e matemática na sociedade do ponto de vista crítico (SAMPAIO, 2010), que permite a tomada de decisões.

Por fim, entende-se que só o direito à igualdade social poderá ser o caminho para lançar luzes no entendimento sobre o fortalecimento econômico do país. Isto só poderá acontecer quando os interesses da elite não forem maiores do que os da nação, bem como as desigualdades raciais na exploração de mão de obra não forem maiores do que a nacionalidade e os interesses do bem comum para o país. Assim, a inserção das cotas raciais deve ser fortalecida no contexto socioeconômico brasileiro, tendo sido uma conquista do movimento negro por meio das políticas públicas implementadas com o decreto $n^{\circ} 7.824 / 2012$. Além disso, tem-se como necessidade criar políticas públicas para evitar a centralização de renda para os mais ricos, contribuindo para a desigualdade social e, sobretudo, para a exploração do trabalho da população mais pobre, em especial, negra. 


\section{UMA PROPOSTA DE SEQUÊNCIA DIDÁTICA PARA ENSINO DE GRÁFICOS ESTATÍSTICOS A PARTIR DA INTERSECCIONALIDADE ENTRE SEXO E RAÇA COM TEMÁTICAS DE UMA ANÁLISE SOCIOECONÔMICA}

\section{REFERÊNCIAS}

AGÊNCIA DO BRASIL. Estruturas econômicas, participação em atividades produtivas, 2018. Disponível em: <http://agenciabrasil.ebc.com.br/geral/noticia/2018-03/ibge-mulheresganham-menos-que-homens-mesmo-sendo-maioria-com-ensino-superior $>$. Acesso em: 21 maio 2019.

ALMEIDA, C. C. Análise de um instrumento de letramento estatístico para o Ensino Fundamental II. Dissertação (Mestrado em Educação Matemática). Universidade Bandeirante de São Paulo, São Paulo, 2010, 109p.

ANDREWS, G. R. Desigualdade racial no Brasil e nos Estados Unidos, 1990-2010. Revista Afro-Asia, 2015, p. 141-174.

BARRETO, R. Angela Davis: radical e libertária. 2017. Disponível em: $<$ https://revistacult.uol.com.br/home/angela-davis-radical-e-libertaria>. Acesso em: 19 jun. 2019.

BATISTA, W. M. A inferiorização dos negros a partir do racismo estrutural. N.4, V.9, Rio de Janeiro: Revista Direito e Práxis, 2018, p. 2581-2589. Disponível em: <http://www.scielo.br/pdf/rdp/v9n4/2179-8966-rdp-9-4-2581.pdf>. Acesso em: 19 jun. 2019.

BATISTA, W. M.; MASTRODI, J. Dos fundamentos extraeconômicos do racismo no Brasil. N.4, v.9, Rio de Janeiro: Revista Direito e Práxis, 2018, p. 2332-2359. Disponível em: <https://www.epublicacoes.uerj.br/index.php/revistaceaju/article/view/30077/23659f>.

Acesso em: 19 jun. 2019.

CANO, W. Desequilíbrios regionais e concentração industrial no Brasil. 1930 - 1970. $3^{\circ}$ edição. Fundação da Editora da Universidade Estadual de São Paulo - UNESP. 2007.

CARVALHO, L. M. T. L.; MONTEIRO, C. E. F.; CAMPOS, T. M. M. Refletindo sobre a interpretação de gráficos como uma atividade de resolução de problemas. In: LOPES, C. E.; COUTINHO, C. Q. S.; ALMOULOUD, S. A. (Orgs.). Estudos e reflexões em educação estatística. Campinas: Mercado de Letras, p. 213-227, 2010.

CASTRO, B. N.; STAMM, C. Diferenças salariais de sexo e raça no mercado de trabalho brasileiro: uma análise estatística e econométrica. In: ENCONTRO NACIONAL DE ESTUDO DE POPULAÇÃO, 2016, Foz do Iguaçu. Anais... XX Encontro Nacional de Estudo de População, 2016.

CAZORLA, I. M.; KATAOKA, V. Y.; SILVA, C. B. Trajetória e perspectivas da educação estatística no Brasil: um olhar a partir do GT 12. In: LOPES, C. E.; COUTINHO, C. Q. S.; ALMOULOUD, S. A. (Orgs.). Estudos e reflexões em educação estatística. Campinas: Mercado de Letras, p. 19-44, 2010. 


\section{UMA PROPOSTA DE SEQUÊNCIA DIDÁTICA PARA ENSINO DE GRÁFICOS ESTATÍSTICOS A PARTIR DA INTERSECCIONALIDADE ENTRE SEXO E RAÇA COM TEMÁTICAS DE UMA ANÁLISE SOCIOECONÔMICA}

CAZORLA, I. M.; OLIVEIRA, M. S. Para saber mais. In: CAZORLA, I. M.; SANTANA, E. R. S. (Org.). Do tratamento da informação ao letramento estatístico. Itabuna: Via Litterarum, p. 113-144, 2010.

COLLINS, P. H. Comentário sobre o artigo de Hekman "Truth and Method: Feminist Standpoint Theory Revisited": onde está o poder? Signis, v.22, n.2, p.375-381, 1997. [Tradução de Juliana Borges].

CURCIO, F. Comprehension of mathematical relationship expressed in graphs. Journal for Research in Mathematics Education. Reston, v. 18, n. 5, 1987, p. 382-393.

D'AMBROSIO, U. Um enfoque transdisciplinar à educação e à história da educação matemática. In: BICUDO, M. A. V.; BORBA, M. C. (Orgs.). Educação Matemática: pesquisa em movimento. São Paulo: Cortez, p. 13-29, 2004.

DAVIS, A. Mulheres, raça e classe. Tradução de Heci Regina Candiani. São Paulo: Boitempo, 2016.

DIEESE, Departamento Intersindical de Estatística e Estudos Socioeconômicos. A situação do trabalho no Brasil. São Paulo: DIEESE, 2008.

DINIZ, L. N. Leitura, construção e interpretação de gráficos estatísticos em projetos de modelagem matemática com uso das tecnologias de informação e comunicação. 2016. Tese (Doutorado em Ciências da Educação) - Instituto de Educação, Universidade do Minho, BragaPortugal, 2016.

GAL, I. Adult statistical literacy: meaning, components, responsabilities. International Statistical Review, v. 70, n. 1, p. 1-25, 2002.

LANGONI, C. G. Distribuição da renda e desenvolvimento econômico do Brasil. $2^{\mathrm{a}}$ ed. Rio de Janeiro: Expressão e Cultura. 1978

LESSA, C. Quinze anos de política econômica. 4ª ed. Brasília: Editora Brasiliense, 1983.

LIMA, M. Desigualdades raciais e políticas públicas: ações afirmativas no governo Lula, 2010. Disponível em: <http://www.scielo.br/scielo.php?script=sci_arttext\&pid=S010133002010000200005>. Acesso em: 21 jun. 2019.

MATOS, R. S.; MACHADO, A. F. Diferencial de rendimentos por cor e sexo no Brasil (1987- 2001). Econômica, Rio de Janeiro, v. 8, n.1, p. 5-27, jun. 2006.

MEDEIROS, C. A. Industrialização e regime salarial na economia brasileira: os anos 60 e 70. Economia e Sociedade, v.2, n.1, p. 125-143, 2016.

MINAYO, M. C. S. Ciência, técnica e arte: o desafio da pesquisa social. In: MINAYO, Revista RBBA Revista Binacional Brasil Argentina 


\section{UMA PROPOSTA DE SEQUÊNCIA DIDÁTICA PARA ENSINO DE GRÁFICOS ESTATÍSTICOS A PARTIR DA INTERSECCIONALIDADE ENTRE SEXO E RAÇA COM TEMÁTICAS DE UMA ANÁLISE SOCIOECONÔMICA}

M. C. S. (Org.) Pesquisa social: teoria, método e criatividade. Petrópolis, RJ: Vozes, p. 9-29, 2004.

MONTEIRO, C. E. F. Explorando a complexidade da interpretação de gráficos entre professores em formação inicial. Cadernos de Estudos Sociais, Recife-PE, v. 22, n. 2, p. 211224, 2006.

PONTE, J. P.; BROCARDO, J.; OLIVEIRA, H. Investigações matemáticas na sala de aula. Belo Horizonte: Autêntica, 2003.

RIBEIRO, D. Lugar de fala. São Paulo: Sueli Carneiro; Pólen, 2019, 112p.

SÁ, D. L.; SILVA, M; P. M.; SAMÁ, S. Análise do letramento estatístico de estudantes concluintes do ensino médio. In: SAMÁ, S.; SILVA, M; P. M. (Org.). Educação Estatística: ações e estratégias pedagógicas no Ensino Básico e Superior. Curitiba: Editora CRV, 2015, p. $155-167$.

SAMPAIO, L. O. Educação estatística crítica: uma possibilidade? Dissertação (Mestrado em Educação Matemática) - Instituto de Geociências e Ciências Exatas, Universidade Estadual Paulista, Rio Claro-SP, 2010.

SHULMAN, L. S. Those who understand: Knowledge growth in teaching. Educational Researcher, Whashington-DC, v. 15, n. 2, p. 4-14, 1986.

SILVA, W. S. População Economicamente Ativa - PEA, 2014. Disponível em: <https://www.infoescola.com/geografia/populacao-economicamente-ativa/>. Acesso em: 19 jun. 2019.

SERRA, J. A reconcentração da renda: justificações, explicações dúvidas. In: TOLIPAN, R.; TINELLI, A. C. (Org.). A controvérsia sobre distribuição de renda e desenvolvimento. $2^{\mathrm{a}}$ ed. Rio de Janeiro: Ed. Zahar. 1975.

SOARES, S. S. D. O perfil da discriminação no mercado de trabalho: homens negros, mulheres brancas e mulheres negras. Brasília: IPEA, p. 1-26, nov. 2000.

TAVARES, M. C. A industrialização brasileira: uma tentativa de reinterpretação. $3^{\mathbf{a}}$ ed. Campinas: UNICAMP, Instituto de Economia. 1998.

WILD, C.; PFANNKUCH, M. Statistical thinking in empirical enquiry. International Statistical Review, Voorburg, v. 67, n. 3, p. 223-248, 1999. 


\section{SOBRE OS AUTORES}

Ivanise Gomes Arcanjo Diniz é Professora do Centro Territorial de Educação Profissional do Vale do Jiquiriçá (CETEP), colégio da rede pública estadual da Bahia, atuando nas áreas de História da Educação Matemática e Educação Estatística. Doutoranda e Mestre em Ensino, Filosofia e História das Ciências pela Universidade Federal da Bahia (UFBA). Tem Especialização em Educação Matemática pela Universidade do Estado da Bahia (UNEB) e em Metodologia do Ensino da Matemática pela Faculdade de Ciências da Bahia. Tem licenciatura em Matemática pela UNEB. É membro do Grupo de Pesquisa Laboratório de Integração e Articulação entre Pesquisas em Educação Matemática e Escola (LIAPEME).

Endereço eletrônico: ivanisegomesster1@gmail.com

Orcid: https://orcid.org/0000-0002-4427-8528

Leandro do Nascimento Diniz é Professor Adjunto da Universidade Federal do Recôncavo da Bahia (UFRB), Centro de Formação de Professores/Amargosa, atuando nas áreas de Educação Estatística, Modelagem Matemática na Educação Matemática, Feiras de Matemática e Tecnologias Digitais no Ensino da Matemática. Doutor em Ciências da Educação pela Universidade do Minho (UMinho). Tem Mestrado em Educação Matemática pela Universidade Estadual Paulista (UNESP), Especialização em Educação Matemática pela Universidade Católica do Salvador (UCSAL). É licenciado em Matemática pela Universidade Federal da Bahia (UFBA). É membro do Grupo de Pesquisa Educação Matemática no Recôncavo da Bahia (GPEMAR) e do Grupo de Estudos e Pesquisas Educação Matemática em Foco (EMFoco).

Endereço eletrônico: leandro@ufrb.edu.br Orcid: http://orcid.org/0000-0002-5583-9001 


\section{UMA PROPOSTA DE SEQUÊNCIA DIDÁTICA PARA ENSINO DE GRÁFICOS ESTATÍSTICOS A PARTIR DA INTERSECCIONALIDADE ENTRE SEXO E RAÇA COM TEMÁTICAS DE UMA ANÁLISE SOCIOECONÔMICA}

Luís Rodrigo Ferreira Santos é estudante de graduação do Curso de Licenciatura em Filosofia da Universidade Federal do Recôncavo da Bahia (UFRB), Centro de Formação de Professores / Amargosa. É membro do Grupo de Estudos Fenomenologia e Existência.

Endereço eletrônico: luisferreirasants@gmail.com

Orcid: https://orcid.org/0000-0001-8484-1699

\section{Notas}

${ }^{\mathrm{i}}$ Neste artigo, considera-se população negra sem distinguir pardos e pretos.

ii Links do IBGE consultados:

IBGE - Instituto Brasileiro de Geografia e estatística. Crescimento demográfico. Disponível em: $<$ https://agenciadenoticias.ibge.gov.br/agencia-sala-de-imprensa/2013-agencia-de-noticias/releases/22374-ibgedivulga-as-estimativas-de-populacao-dos-municipios-para-2018>. Acesso em: 21 jun. 2019; IBGE - Instituto Brasileiro de Geografia e estatística. Indicadores sociais. Disponível em: $<$ https://agenciadenoticias.ibge.gov.br/agencia-sala-de-imprensa/2013-agencia-de-noticias/releases/23298-

sintese-de-indicadores-sociais-indicadores-apontam-aumento-da-pobreza-entre-2016-e-2017>. Acesso em: 21 jun. 2019; IBGE - Instituto Brasileiro de Geografia e estatística. PAS - Pesquisa Anual de Serviços. Disponível em: <http://www.ipeadata.gov.br>. Acesso em: 21 jun. 2019; IBGE - Instituto Brasileiro de Geografia e estatística. PIB. Disponível em: <https://agenciadenoticias.ibge.gov.br/agencia-sala-de-imprensa/2013-agencia-denoticias/releases/23419-pib-dos-municipios-2016-semiarido-responde-por-5-1-do-pib-do-pais>. Acesso em: 21 jun. 2019.

iii $\mathrm{O}$ coeficiente de Gini (ou índice de Gini) é um cálculo usado para medir a desigualdade social, desenvolvido pelo estatístico italiano Corrado Gini, em 1912. Apresenta dados entre o número 0 e o número 1, onde zero corresponde a uma completa igualdade na renda (onde todos detêm a mesma renda per capita) e um que corresponde a uma completa desigualdade entre as rendas (onde um indivíduo, ou uma pequena parcela de uma população, detêm toda a renda e os demais nada têm).

iv Os institutos e órgãos governamentais, citados neste artigo, consideram que a raça/cor negra é para as pessoas pretas e pardas e as não-negras são as brancas e amarelas. Por conta desta restrição, os dados sobre a diferença entre raça preta e parda não foram abordados. Reitera-se, contudo, que as pesquisas sobre a discriminação racial e o preconceito de cor (entre pretos e pardos) no Brasil vêm sendo discutidas em órgãos como a Fundação Perseu Abramo e o Instituto Data Folha, além de diversas pesquisas qualitativas.

${ }^{v}$ A PEA é formada pela população trabalhadora com idade entre 10 e 65 anos (no Brasil) que recebe remuneração salarial pela venda de sua força de trabalho (SILVA, 2014).

Recebido em: 13/05/2020

Aprovado em: 15/06/2020

Publicado em: 01/07/2020 